\title{
Differential Contributions of GABA Concentration in Frontal and Parietal Regions to Individual Differences in Attentional Blink
}

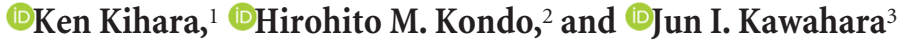 \\ ${ }^{1}$ Graduate School of Science and Engineering, Kagoshima University, Kagoshima 890-0065, Japan, ${ }^{2}$ NTT Communication Science Laboratories, NTT \\ Corporation, Kanagawa 243-0198, Japan, and ${ }^{3}$ Graduate School of Letters, Hokkaido University, Sapporo 060-0810, Japan
}

Selective attention plays an important role in identifying transient objects in a complex visual scene. Attentional control ability varies with observers. However, it is unclear what neural mechanisms are responsible for individual differences in attentional control ability. The present study used the following attentional blink paradigm: when two targets are to be identified in rapid serial visual presentation, the processing of the first target interrupts the identification of the second one appearing within $500 \mathrm{~ms}$ after the first-target onset. It has been assumed that the reduction of the second-target accuracy is mainly due to a transient inhibition of attentional reorienting from the first to the second target, which is modulated by the GABA system. Using magnetic resonance spectroscopy, we investigated whether individual variation of attentional blink magnitude is associated with GABA concentrations in the left prefrontal cortex (PFC), right posterior-parietal cortex (PPC), and visual cortex (VC) of humans. GABA concentrations in the PFC were related negatively to attentional blink magnitude and positively to the first-target accuracy. GABA concentrations in the PPC were positively correlated with attentional blink magnitude. However, GABA concentrations in the VC did not contribute to attentional blink magnitude and first-target accuracy. Our results suggest that frontoparietal inhibitory mechanisms are closely linked with individual differences in attentional processing and that functional roles of the GABAergic system in selective attention differ between the PFC and PPC.

Key words: attentional blink; frontoparietal regions; GABA; individual differences; magnetic resonance spectroscopy (MRS); visual attention

\section{Significance Statement}

Selective attention is the process of picking up task-relevant information in the environment. Attentional blink reflects time constraints of visual attention. It has been assumed that attentional blink is induced by the inhibition of attentional reorienting to other objects. This study used magnetic resonance spectroscopy to noninvasively measure concentrations of GABA, the principal inhibitory neurotransmitter, in the human brain. We show that a neural interaction between GABA concentrations in the prefrontal and posterior parietal regions accounts for the interindividual variability of attentional blink magnitude. Our results provide direct evidence that the GABAergic system in the frontoparietal networks is responsible for temporal aspects of attentional control ability.

\section{Introduction}

The visual system processes scenes in a split second. However, selective attention processing is performed in a serial fashion for

\footnotetext{
Received March 3, 2016; revised July 4, 2016; accepted July 7, 2016.

Author contributions: K.K., H.M.K., and J.I.K. designed research; K.K., H.M.K., and J.I.K. performed research; K.K. and H.M.K. analyzed data; K.K., H.M.K., and J.I.K. wrote the paper.

This study was supported by the Japan Society for the Promotion of Science (Grant-in-Aid 26285168 to J.I.K.). We thank Keith Heberlein, Mark A. Brown, and Heiko Meyer for providing the GABA spectral editing sequence (a work-in-progress version) and Yasuhiro Shimada and Takanori Kochiyama for helping with imaging data collection.

The authors declare no competing financial interests.

Correspondence should be addressed to Ken Kihara, Graduate School of Science and Engineering, Kagoshima

University, 1-21-40, Korimoto, Kagoshima 890-0065, Japan. E-mail: kihara@ibe.kagoshima-u.ac.jp.
}

the identification of items and events in a visual scene. Attentional blink reflects such a fundamental aspect of selective attention (Raymond et al., 1992). In a rapid serial visual presentation (RSVP) paradigm, stimuli are presented sequentially at the same position. Observers are instructed to detect the first and second targets embedded in a sequence of distractors. The firsttarget identification impairs the second-target identification when the stimulus onset asynchrony (SOA) between the first and second targets is $<\sim 500 \mathrm{~ms}$. This gap between the two targets indicates a temporal limit for reorienting attention from the first 
Table 1. Correlations between neurotransmitter concentrations and behavioral indices

\begin{tabular}{|c|c|c|c|c|c|c|c|c|c|c|c|c|}
\hline \multirow[b]{2}{*}{ Condition } & \multicolumn{4}{|l|}{ PFC } & \multicolumn{4}{|l|}{ PPC } & \multicolumn{4}{|l|}{ VC } \\
\hline & $r$ & $p$ & $r_{\mathrm{s}}$ & $p$ & $r$ & $p$ & $r_{\mathrm{s}}$ & $p$ & $r$ & $p$ & $r_{\mathrm{s}}$ & $p$ \\
\hline \multicolumn{13}{|c|}{ AB magnitude } \\
\hline Normal & -0.62 & $<0.01$ & -0.55 & $<0.01$ & 0.51 & $<0.02$ & 0.59 & $<0.01$ & -0.16 & 0.48 & -0.33 & 0.12 \\
\hline Difficult & -0.23 & 0.30 & -0.21 & 0.32 & 0.45 & $<0.04$ & 0.44 & $<0.04$ & 0.11 & 0.61 & 0.09 & 0.67 \\
\hline \multicolumn{13}{|c|}{ First-target accuracy } \\
\hline Normal & 0.54 & $<0.01$ & 0.48 & $<0.02$ & -0.08 & 0.74 & -0.17 & 0.41 & 0.22 & 0.33 & 0.13 & 0.53 \\
\hline Difficult & 0.28 & 0.19 & 0.26 & 0.21 & -0.35 & 0.11 & -0.22 & 0.30 & 0.26 & 0.23 & 0.39 & 0.06 \\
\hline
\end{tabular}

to second target (for a recent review, see Martens and Wyble, 2010).

There is interindividual variability in attentional blink magnitude (i.e., the size of the attentional deficit), which is defined as the difference in the second-target accuracies between short and long SOAs (MacLean and Arnell, 2012). In general, shorter SOAs lead to larger reduction of the second-target accuracy. However, it is known that $\sim 5 \%$ of population, called nonblinkers, does not show significant attentional blink (Martens and Wyble, 2010). Consider what neural mechanisms affect individual differences in attentional blink magnitude. It has been found that the prefrontal cortex (PFC) and posterior-parietal cortex (PPC) are neural bases of processes related to attentional blink (Hommel et al., 2006; Husain and Nachev, 2007; Kihara and Takeda, 2012; Raffone et al., 2014; Glennon et al., 2016). Specifically, the PFC is more activated for nonblinkers than for blinkers (Feinstein et al., 2004). Patterns of the second-target-related P300 component in the frontal areas differ between blinkers and nonblinkers (Martens et al., 2006). Alpha- and beta-band oscillations in frontal and parietal areas during a resting state are correlated with individual differences in attentional blink magnitude (MacLean et al., 2012). These findings indicate that differences in attentional blink magnitude are derived from frontoparietal functions for each individual.

Many researchers have postulated that the inhibition of bottom-up attention is associated with attentional blink (Raymond et al., 1992; Fragopanagos et al., 2005; Olivers and Meeter, 2008; Taatgen et al., 2009; Wyble et al., 2009; Kihara et al., 2011; Simione et al., 2012; Raffone et al., 2014). Specifically, a transient inhibition of bottom-up attention occurs after the onset of the first target and continues for half a second to protect the firsttarget processing against interference from irrelevant information of other RSVP items. Therefore, the second target appearing during the inhibitory period cannot receive attentional processing, leading to attentional blink. Inhibition functions are probably modulated by the GABA system. For instance, attentional blink magnitude is increased with the administration of benzodiazepines (i.e., GABA agonists; Boucart et al., 2000; Boucart et al., 2007). In pharmacological studies in humans, however, it is essentially difficult to specify what brain areas are affected by the GABAergic system.

From a neurochemical perspective, we examined what brain areas play an important role in attentional control during an attentional blink task. Magnetic resonance spectroscopy (MRS) was used to quantify regional GABA concentrations in the human brain. The visual cortex (VC), as well as the PFC and PPC, was chosen as a voxel of interest (VOI). In contrast to the PFC and PPC, the VC does not contribute directly to attentional control for the detection of RSVP targets (Marois et al., 2004; Choi et al., 2012). We hypothesized that GABA concentrations in the PFC and PPC are correlated with individual differences in attentional blink magnitude, but those in the VC are not.

\section{Materials and Methods}

Participants. Twenty-nine subjects (24 males and 5 females, mean age 31.4 years, range 21-58) participated in this experiment. All were righthanded Japanese subjects with normal or corrected-to-normal vision. Five participants were excluded due to lack of MRS data in any VOI. The distribution of neurotransmitter measures followed a normal distribution (Kolmogorov-Smirnov test, $p>0.16$ ). However, a SmirnovGrubbs test showed that GABA signals of two participants were outliers (one showed a signal of 0.19 in the PPC and the other showed a signal of 0.30 in the VC). Therefore, these two were removed from the dataset, making the sample size 22. The results based on Pearson's correlations were essentially the same as those based on Spearman's rank order correlations (Table 1). Therefore, the former case is reported below. Written informed consent was obtained from all participants. The study was performed in accordance with the Declaration of Helsinki and was approved by the Ethics and Safety Committees at NTT Communication Science Laboratories and ATR-Promotions.

Attentional blink task. A stream of visual stimuli consisted of two targets and 26 distractors. Targets were different letters chosen from A to Y except for I, O, and Q. The distractors were randomly chosen digits (1-9) with a constraint that the same digit was not presented successively. The number of distractors before the first target varied between six and 10. Each item (visual angle, $1.0^{\circ}$ ) appeared for $100 \mathrm{~ms}$ without an interstimulus interval. The items, colored in white $\left(261.6 \mathrm{~cd} / \mathrm{m}^{2}\right)$, were presented against a black background $\left(0.3 \mathrm{~cd} / \mathrm{m}^{2}\right)$. Stimuli were presented on a 23-inch LCD monitor driven at a $60 \mathrm{~Hz}$ refresh rate and controlled by MATLAB (RRID: SCR_001622) with the Psychophysics Toolbox (Brainard, 1997; Pelli, 1997; RRID: SCR_002881). The viewing distance was $\sim 57 \mathrm{~cm}$.

In this study, we used a 3 (intertarget SOA) $\times 2$ (first-target difficulty) within-subject design. Following conventional attentional blink procedures (MacLean and Arnell, 2012), we set three levels of intertarget SOAs. The second target was presented as the second, third, or eighth item after the first target (i.e., 200, 300, or $800 \mathrm{~ms}$ SOAs). A masked or unmasked first target was used to control the performance level of the first-target accuracy (difficult and normal conditions). This manipulation was intended to avoid a too-easy load for potential nonblinkers. The first-target masking generally induces the reduction of the first-target accuracy, yielding an enlargement of the attentional blink (Seiffert and Di Lollo, 1997).

A cross-hair fixation was presented at the beginning of each trial (Fig. 1). Participants were instructed to start a trial at their own pace and identify two targets in an RSVP stream. At the end of the stream, participants were asked to indicate letters by a key press corresponding to targets. There was neither time pressure for their answer nor feedback about their performance. This experiment consisted of a total of 150 trials, including 25 repeats for six conditions. Trials were randomized across the participants. Before an experimental session, participants performed 12 practice trials. It took $\sim 20 \mathrm{~min}$ to complete the task.

MRS data acquisition. To minimize confounding factors affecting neurotransmitter concentrations, we conducted the acquisition of MR spectra at a fixed time from 1:00 P.M. to 2:30 P.M. Data were acquired with a 3 T MRI scanner with a 12-channel receive-only head coil (MAGNETOM Trio; Siemens). Head motion was minimized with comfortable padding around the participant's head. For assessment of cortical thickness and volume, anatomical images were obtained with a T1-weighted pulse sequence (isotropic voxel size of $1 \mathrm{~mm}^{3}$ ). MR spectra were acquired from 


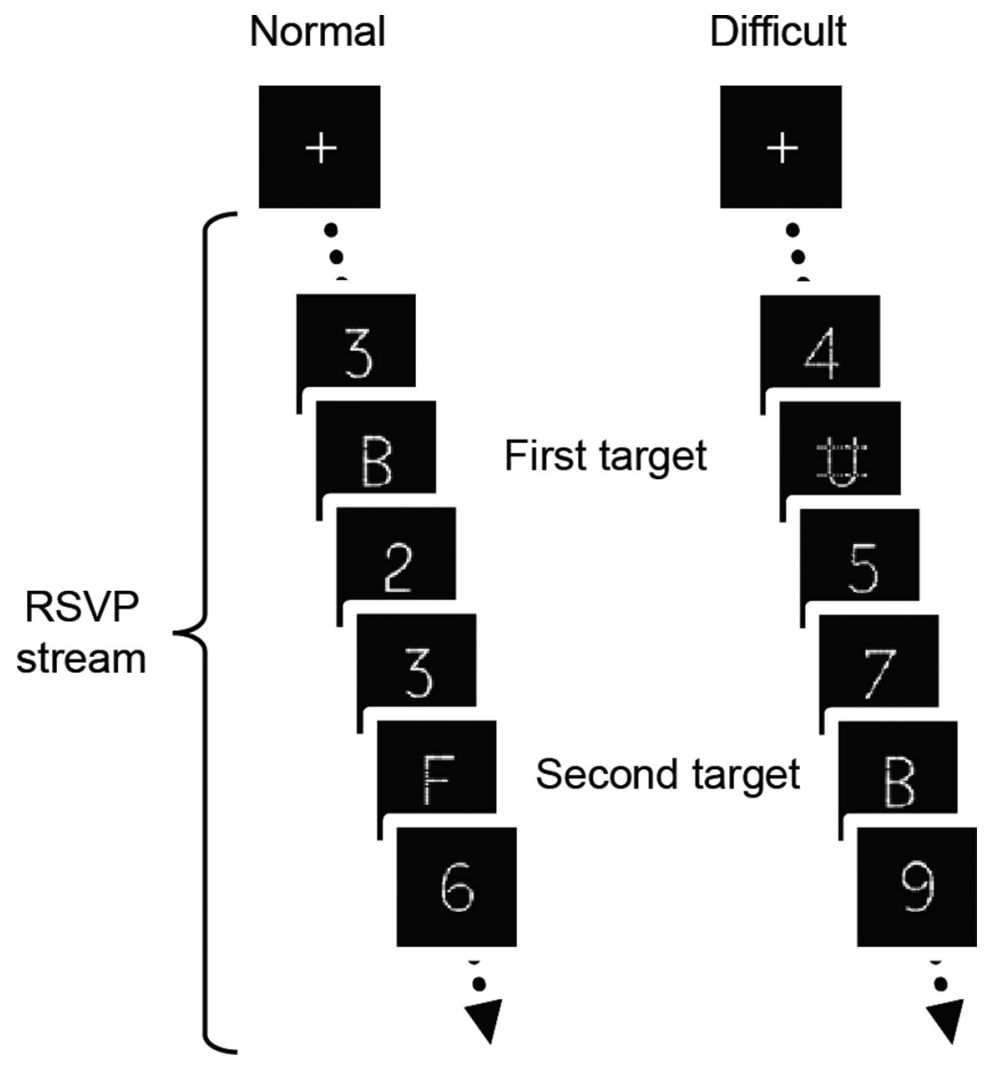

Figure 1. Schematic illustration of the RSVP paradigm. Each item was presented for $100 \mathrm{~ms}$ without an interstimulus interval. The first target was masked by the equal sign under the difficult condition, but not under the normal condition.

Data analysis. Identified targets were scored as correct responses regardless of participant's report order. The second-target accuracy was based on only trials in which the first target had been detected correctly. Attentional blink magnitude was computed by subtracting the second-target accuracy averaged across the 200 and $300 \mathrm{~ms}$ SOAs from the second-target accuracy at the $800 \mathrm{~ms}$ SOA because the behavioral index is suitable for the assessment of interindividual variability of attentional blink (Kawahara and Kihara, 2011; MacLean and Arnell, 2012). We performed a repeated-measures ANOVA on behavioral performance. Tukey HSD tests were used as post hoc comparisons $(\alpha$-level $=0.05)$. Pearson correlation coefficients $(r)$ were computed to estimate the relationship between the behavioral indices and MRS data. Neurotransmitter measures were obtained from the three brain regions (PFC, $\mathrm{PPC}$, and VC). To control for regional effects of neurotransmitters, we calculated partial correlation coefficients ( $p r$ ) between firsttarget accuracy and each GABA measure and between attentional blink magnitude and each GABA measure. Statistical analyses were performed in Statistica 6.1 (Statsoft) and R 3.2.1. (www.r-project.org).

\section{Results}

The accuracy for target identification is shown in Figure 3. We performed a $3 \times 2$ ANOVA on the second-target accuracy. The second-target accuracy was lower at

three $3 \times 3 \times 3 \mathrm{~cm}^{3}$ VOIs positioned in the PFC, PPC, and VC (Fig. $2 A$ ). Voxels were positioned using internal landmarks to achieve a consistent position across participants. Note that MR spectra could not be measured from both hemispheres at the same time. Accordingly, we selected the left PFC and right PPC as VOIs because these regions are considered as critical regions involved in the control of temporal attention during the attentional blink (Hommel et al., 2006). The left PFC voxel was located at the anterior part of the middle frontal gyrus (BA 46). The right PPC voxel was placed on the intraparietal sulcus (BA 7) and the voxel included a part of the superior and inferior parietal lobules. The $\mathrm{VC}$ voxel was centered bilaterally on the calcarine sulcus (BA 17).

Three consecutive runs were acquired for each participant from the different voxels. Before each run, we carefully performed manual shimming ( $\sim 5 \mathrm{~min}$ ) of the magnetic field in the voxel to avoid line broadening. MR spectra were obtained using a GABA spectral editing sequence. For each spectrum, 64 spectral averages of 1024 data points were acquired with a repetition time of $1500 \mathrm{~ms}$ and an echo time of $68 \mathrm{~ms}$, resulting in a scan duration of $3 \mathrm{~min} 18 \mathrm{~s}$. In a preliminary study, we identified that the data quality did not differ among 64, 128, and 256 spectral averages. Therefore, we used the shorter duration to reduce effects of head motion on MR spectra. An editing pulse with bandwidth of $44 \mathrm{~Hz}$ was applied at $1.9 \mathrm{ppm}$ (on) and $7.5 \mathrm{ppm}$ (off) in interleaved scans. The difference in the edited spectra yielded the GABA peak (Fig. 2B). For MRS data analysis, GANNET and in-house software was used to quantify total GABA in the difference spectra (Edden et al., 2014). All spectra were phase and frequency aligned to creatine $(\mathrm{Cr})$ and modeled with a simple Gaussian function. The final results were expressed as the ratio of GABA signal areas (a peak at $3.00 \mathrm{ppm}$ ) relative to the $\mathrm{Cr}$ area. The GABA concentrations were quantified in institutional units (i.u.) (Mullins et al., 2014). The GABA concentrations (mean \pm SE) were $0.140 \pm 0.012$ i.u. for the left PFC, $0.113 \pm 0.005$ i.u. for the right PPC, and $0.148 \pm 0.009$ i.u. for the VC. The fit errors related to the GABA values were $13.5 \pm$ $0.7 \%$ for the left PFC, $11.9 \pm 0.5 \%$ for the right PPC, and $9.4 \pm 0.3 \%$ for the VC. Therefore, the reliability of neurotransmitter levels reached generally a satisfactory level because the fit errors were $\sim 10 \%$. the 200 and $300 \mathrm{~ms}$ SOAs $(54.5 \pm 5.6 \%$ and $48.8 \pm 6.1 \%$, respectively) than at the $800 \mathrm{~ms}$ SOA $(84.4 \pm 3.6 \%)\left(F_{(2,42)}=38.09, p<\right.$ $\left.0.001, \eta_{p}^{2}=0.64\right)$. This indicates that attentional blink occurred in the expected time window. The second-target accuracy was lower under the difficult condition $(56.7 \pm 6.6 \%)$ than under the normal condition $(68.4 \pm 5.4 \%)\left(F_{(1,21)}=17.26, p<0.001, \eta_{p}^{2}=\right.$ $0.45)$. This suggests that first-target masking affects the secondtarget accuracy. An interaction between intertarget SOA and first-target difficulty was significant $\left(F_{(2,42)}=4.15, p<0.03\right.$, $\left.\eta_{p}^{2}=0.16\right)$. We calculated attentional blink magnitude to evaluate individual differences in the attentional blink effect. Attentional blink magnitude was greater for the difficult condition $(38.7 \pm 6.2 \%)$ than for the normal condition $(26.9 \pm 4.9 \%)$ $\left(t_{(21)}=2.10, p<0.05\right.$, two-tailed). This is consistent with earlier demonstrations of the effect of difficulty on attentional blink magnitude (Seiffert and Di Lollo, 1997), suggesting that the mask superimposed on the first target interferes with attentional reorienting to the second target, which leads to an enlargement of attentional blink magnitude.

We performed a $3 \times 2$ ANOVA on the first-target accuracy, which did not differ among the 200, 300, and 800 ms SOAs: $78.0 \pm 3.9 \%, 81.9 \pm 3.6 \%$, and $81.2 \pm 3.5 \%$, respectively $\left(F_{(2,42)}=2.84, p>0.07, \eta_{p}^{2}=0.12\right)$. The first-target accuracy was higher under the normal condition $(90.4 \pm 2.1 \%)$ than under the difficult condition $(70.3 \pm 3.6 \%)\left(F_{(1,21)}=60.61, p<0.001\right.$, $\left.\eta_{p}^{2}=0.74\right)$. This result observed in the present study is comparable to that in ordinary attentional blink studies (Seiffert and Di Lollo, 1997). The interaction was not significant $\left(F_{(2,44)}=1.22\right.$, $\left.p>0.30, \eta_{p}^{2}=0.05\right)$. Note that the significant attentional blink magnitude was observed in the normal condition, in which there were only two nonblinkers (i.e., the second-target accuracy at 

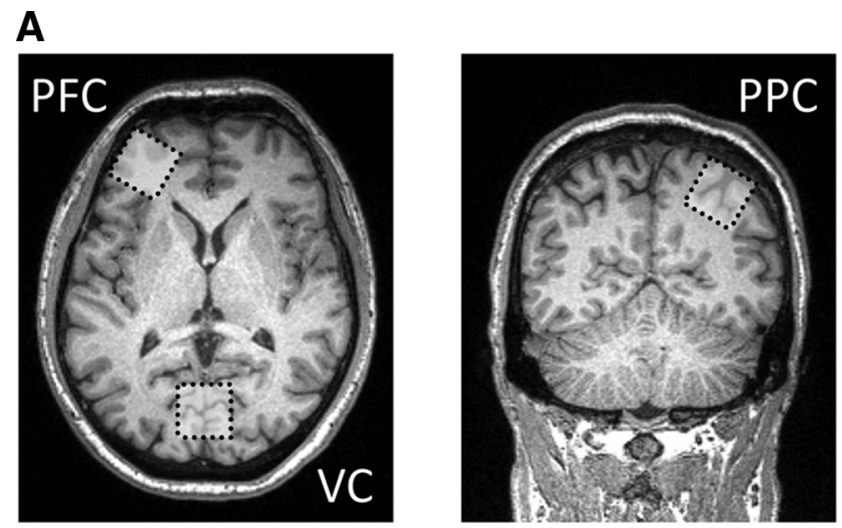

B

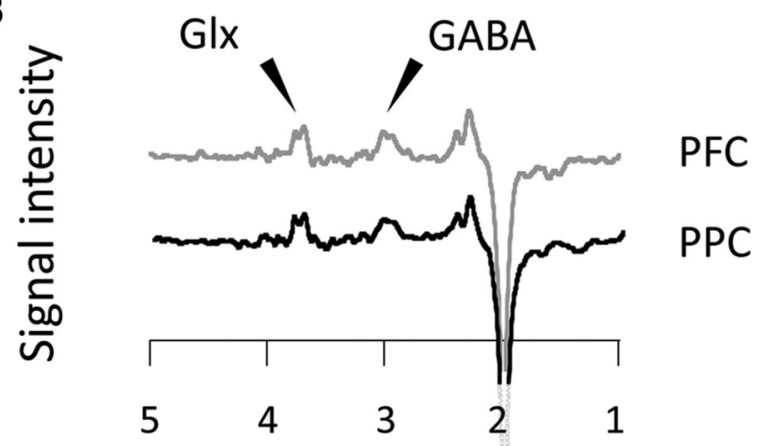

\section{Chemical shift (ppm)}

Figure 2. A, Size and location of V0l. Left and right panels indicate axial and coronal slices, respectively. $B, G A B A$ peak obtained from the differences in spectra by editing radio frequency on/off pulses. The data are derived from a representative participant. The horizontal axis indicates the institutional unit. Glx, Glutamate-glutamine.

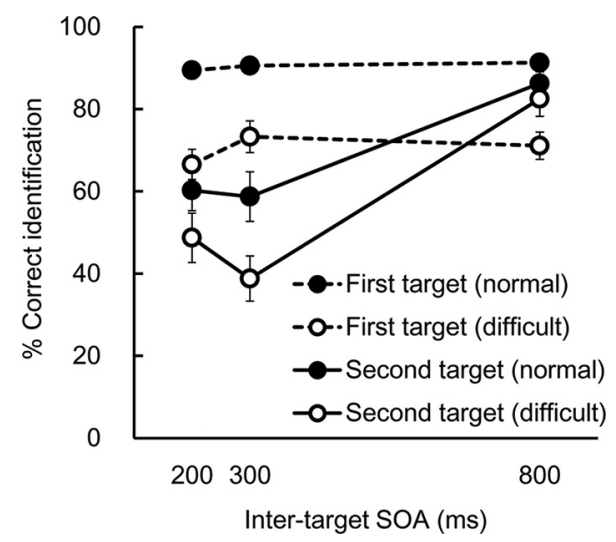

Figure 3. Behavioral results. Shown are mean correct reports of the first target and the second target given correct reports of the first target as a function of intertarget SOA for firsttarget difficulty conditions. Error bars indicate the SEM across participants $(N=22)$.

critical SOAs of 200 and $300 \mathrm{~ms}$ exceeded that at the $800 \mathrm{~ms}$ SOA). This suggests that the first-target identification was difficult enough to produce the attentional blink for most of the participants even when the first target was not masked. Accordingly, the first-target accuracy reflects individual differences in the control of temporal attention, not a ceiling effect. The firsttarget accuracy was significantly correlated with attentional blink magnitude in the normal condition $(r=-0.59, p<0.004)$, but not in the difficult condition $(r=0.19, p>0.39)$, suggesting that the attentional blink magnitude was underestimated in some participants in the difficult condition (see Discussion).

We computed correlation coefficients between GABA concentrations and behavioral indices (Fig. 4). For the normal condition, attentional blink magnitude was related negatively to GABA concentrations in the PFC $(r=-0.62, p<0.003)$ and positively to GABA concentrations in the PPC $(r=0.51, p<$ 0.02). A multiple regression analysis revealed that the GABA concentrations in PFC and PPC accounted for the $61.9 \%$ variance of attentional blink magnitude (adjusted $R^{2}=0.579$, $\left.F_{(2,19)}=15.46, p<0.001\right)$. GABA concentrations in the PFC were correlated with the first-target accuracy $(r=0.54, p<0.01)$. However, GABA concentrations in the PPC were not significantly correlated with the first-target accuracy $(r=-0.08, p>$ $0.73)$. For the difficult condition, GABA concentrations in the PPC were significantly correlated with attentional blink magnitude $(r=0.45, p<0.04)$, but not with the mean first target accuracy $(r=-0.35, p>0.10)$. GABA concentrations in the PFC were neither correlated with attentional blink magnitude $(r=$ $-0.23, p>0.30)$ nor with the first-target accuracy $(r=0.28, p>$ $0.19)$. However, GABA concentrations in the PFC were significantly correlated with the second-target accuracies in the $200 \mathrm{~ms}$ $\operatorname{SOA}(r=0.53, p<0.02)$ and $300 \mathrm{~ms} \mathrm{SOA}(r=0.60, p<0.004)$. In both the normal and difficult conditions, GABA concentrations in the $\mathrm{VC}$ were not significantly correlated with attentional blink magnitude (for the normal condition, $r=-0.16, p>0.48$; for the difficult condition, $r=0.11, p>0.60)$ or with the firsttarget accuracy (for the normal condition, $r=0.22, p>0.32$; for the difficult condition, $r=0.26, p>0.22$ ). Furthermore, using a partial correlation analysis, we specified the contribution of a specific brain region to each behavioral performance by ruling out effects of the other regions. The results showed the same pattern as Pearson's correlation coefficients between GABA concentrations and behavioral indices. For the normal condition, attentional blink magnitude was significantly correlated with GABA concentrations in the PFC ( $p r=-0.67, p<0.001)$ and PPC $(p r=0.63, p<0.002)$, but not with those in the VC $(p r=$ $-0.14, p>0.52)$. The first-target accuracy was significantly correlated with GABA concentrations in the PFC $(p r=0.51, p<$ $0.02)$, but not with those in the PPC ( $p r=-0.09, p>0.69)$ or VC $(p r=0.11, p>0.62)$. For the difficult condition, attentional blink magnitude was significantly correlated with GABA concentrations in the PPC $(p r=0.44, p<0.05)$, but not with those in the PFC $(p r=-0.26, p>0.23)$ or VC $(p r=0.11, p>0.62)$. The first-target accuracy was not correlated with GABA concentrations in the PFC, PPC, or VC $(p r=0.22,-0.41$, and $0.29, p>$ $0.33,0.05$, and 0.18 , respectively). In summary, GABA concentrations in the PPC were positively correlated with attentional blink magnitude in the normal and difficult conditions. In the normal condition, GABA concentrations in the PFC were correlated negatively with attentional blink magnitude and positively with the first-target accuracy.

\section{Discussion}

We tested the hypothesis that GABA concentrations in the left PFC and right PPC affect attentional control during an attentional blink task. Behavioral results were consistent with previous findings that attentional reorienting during a $500 \mathrm{~ms}$ gap between the first and second targets is closely linked to attentional blink magnitude (Raymond et al., 1992). More importantly, a neural interaction between regional GABA levels was found: participants who had higher GABA concentrations in the PFC showed smaller attentional blink magnitude, whereas those who had 

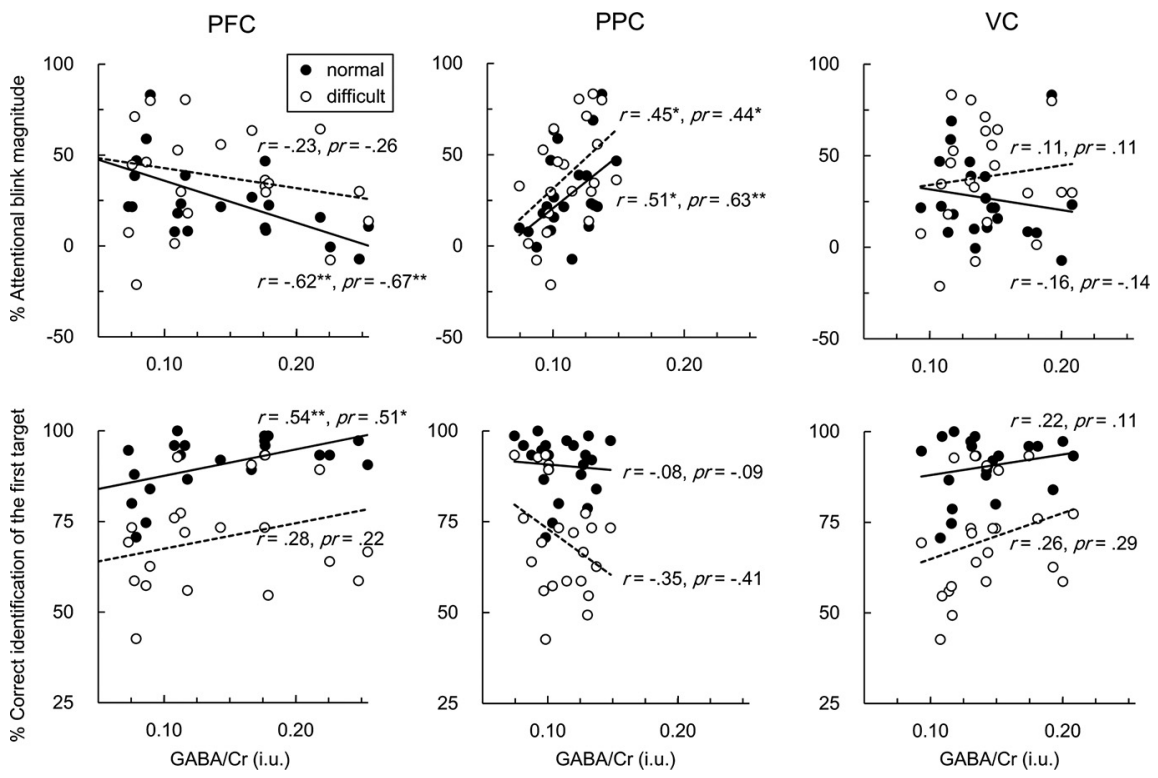

Figure 4. Scatter plots for the relationship between GABA concentrations in each VOI and mean correct reports of attentional blink magnitude (top) and the first target (bottom). The solid and broken lines show linear regression fits to the data from the normal and difficult conditions, respectively. ${ }^{*} p<0.05,{ }^{* *} p<0.01$.

higher GABA concentrations in the PPC showed larger attentional blink magnitude. The attentional blink reflects the failure of temporal orienting of attention from the first to the second target (Raymond et al., 1992; Martens and Wyble, 2010). Therefore, our results indicate that a balance of GABA concentrations in the frontoparietal areas is responsible for individual differences in temporal aspects of attentional control ability. GABA concentrations in the VC did not contribute to individual differences in either the first-target accuracy or attentional blink magnitude. This finding is consistent with our prediction derived from the view that the VC is not involved in the control of attention required for the attentional blink task (Marois et al., 2004; Choi et al., 2012). We discuss below the roles of the PPC and PFC in attentional blink.

GABA concentrations in the right PPC were correlated with attentional blink magnitude, but not with the first-target accuracy. The GABAergic system in the PPC may not be associated with the identification itself of targets embedded in an RSVP stream because attentional blink magnitude in the present study was defined exclusively by the second-target accuracy. Therefore, GABA levels in the PPC are positively linked to the deficit in second-target identification due to failure of attentional reorienting from the first to the second target. Psychological studies have demonstrated that a transient inhibition of attentional reorienting during a $500 \mathrm{~ms}$ gap between the first and second targets plays an important role in attentional blink (Raymond et al., 1992; Fragopanagos et al., 2005; Olivers and Meeter, 2008; Taatgen et al., 2009; Wyble et al., 2009; Kihara et al., 2011; Simione et al., 2012; Raffone et al., 2014). It has been found that the posteriorparietal inhibitory mechanism is involved in the performance of various attentional tasks and, specifically, that the right PPC is probably responsible for attentional blink (Husain and Nachev, 2007; Corbetta et al., 2008). Therefore, it is plausible that the GABAergic system in the right PPC mediates the transient inhibition of attentional reorienting, leading to attentional blink.

GABA concentrations in the left PFC were correlated negatively with attentional blink magnitude and positively with the first-target accuracy under the normal condition. This interaction of the correlations means that the first- and second-target accuracies improve as GABA concentrations increase. Under the difficult condition, GABA concentrations in the left PFC were significantly correlated with the second-target accuracies in the $200 \mathrm{~ms}$ SOA and $300 \mathrm{~ms}$ SOA. This confirms that GABA concentrations are linked to successful identification of visual targets in general. A possible explanation for the correlations related to the first and second target accuracies is that the amount of attention devoted to the first target is suppressed by the GABAergic system. Given a consensus that attentional blink is mainly caused by the assignment of limited attentional resources to the first target (Martens and Wyble, 2010; Arnell and Shapiro, 2011), one may predict that the identification of the first target is improved by increasing attentional resources. This idea can be consistent with the present study based on the finding that excessive attentional resources deteriorate the first-target identification (Olivers and Nieuwenhuis, 2005, 2006). It is likely that GABA concentrations in the PFC are positively related to identification accuracies of both targets because the following stimulus interferes with the identification processing of the first target (Potter et al., 2004; Bachmann and Hommuk, 2005) and the interference increases if attentional resources become more available (Lavie, 1995). Therefore, GABA concentrations in the PFC would be positively related to identification accuracies of both targets.

Another explanation is that GABA concentrations in the PFC contribute to the top-down attentional control for identifying the targets. In the attentional blink paradigm, observers have to form an attentional set for detecting specific features of targets in a top-down manner (Di Lollo et al., 2005; Olivers and Meeter, 2008). Neuroimaging studies have demonstrated that the left PFC is responsible for the maintenance of the task set (Dosenbach et al., 2006; Mayr et al., 2006; Banich, 2009) and PFC activity is increased with successful detection of the first and second targets (Hommel et al., 2006). Therefore, identification accuracies of both targets depend on the top-down attentional set for target properties maintained by the left PFC. Taking the findings of the present study and previous ones into account, we can expect that the GABAergic system in the left PFC plays a critical role in maintaining top-down attention throughout a trial. Unfortunately, the present study was not designed to distinguish which explanation is more plausible. However, the two explanations are not necessarily mutually exclusive because the attentional blink is thought to be caused by multiple factors (Kawahara et al., 2006; Martens and Wyble, 2010). Therefore, the GABAergic system in the PFC could contribute to the reduction of attentional resources to the first target and the control of the attentional set for target identification.

A possible reason for the null correlations between left prefrontal GABA levels and behavioral performance in the difficult condition might be the relatively low second-target accuracy at $800 \mathrm{~ms}$ in some participants $(n=5)$, whose performance decreased $>15 \%$ in the difficult condition. Such reduced secondtarget accuracy at a longer SOA has occasionally been reported when the first target task is very difficult (Kihara et al., 2007). In that case, the attentional blink period is extended and thus the 
attentional blink magnitude is underestimated accordingly. In fact, we found significant negative correlations for the first-target accuracy and attentional blink magnitude in the normal condition, but not in the difficult condition. We infer that the impact of the first-target difficulty manipulation differed across participants, resulting in the lack of a significant correlation under the difficult condition. Notably, the first-target accuracy was lower in those participants relative to others, probably due to suboptimal use of the attentional setting. The data from those participants are likely to contribute to the null correlation between the first-target accuracy and GABA concentrations in the left PFC.

The present study focusing on the control of temporal attention also has implications for the frontoparietal GABAergic system underlying the spatial characteristics of attention. Several studies have demonstrated that attentional blink magnitude depends, not only on the temporal lag, but also on the spatial distance from the first to second targets. For example, Kristjánsson and Nakayama (2002) reported that attentional blink magnitude decreases with increasing spatial distance between the two targets (for similar results, see also Du et al., 2011). Kristjánsson and Nakayama discussed their findings in terms of lateral inhibition. That is, attending to the first target causes a transient inhibitory zone (at least $\sim 9^{\circ}$ of visual angle in diameter) surrounding the location of the first target. Therefore, GABA-mediated inhibitory mechanisms in the PPC and PFC observed in this study would be involved in both temporal and spatial limitation of visual attention.

In conclusion, the present study shows that GABA concentrations in the right PPC and left PFC are correlated with attentional blink magnitude in the opposite directions. In addition, GABA levels in the PFC are related to the first-target accuracy. These results suggest that the right posterior-parietal GABAergic system is critical for transient inhibition of attentional reorienting toward the second target during the attentional blink period, whereas the left prefrontal GABAergic system contributes to decreasing attentional resources to the first target and/or attentional processing for identifying the target(s) embedded in RSVP distractors in general. In addition, GABA concentrations in the VC are not correlated with accuracies for either target, suggesting that GABAergic functions in the VC are not involved in the attentional processing for the RSVP task. Although the involvements of the frontoparietal cortices (Martens et al., 2006) and GABA concentrations (Boucart et al., 2007) in attentional blink have been examined individually, the present results demonstrate the direct connection between such regions and GABAergic functions regarding attentional blink. Therefore, we can consider that the PPC and PFC activities observed in previous attentional blink studies reflect GABA-mediated attentional processing. Our findings suggest that individual differences in attentional blink depend on inhibitory mechanisms of the PFC and PPC regions, in which concentrations have different effects on the first- and second-target identifications.

\section{References}

Arnell KM, Shapiro KL (2011) Attentional blink and repetition blindness. Wiley Interdiscip Rev Cogn Sci 2:336-344. CrossRef Medline

Bachmann T, Hommuk K (2005) How backward masking becomes attentional blink: perception of successive in-stream targets. Psychol Sci 16: 740-742. CrossRef Medline

Banich MT (2009) Executive function: the search for an integrated account. Curr Dir Psychol Sci 18:89-94. CrossRef

Boucart M, de Visme P, Wagemans J (2000) Effect of benzodiazepine on temporal integration in object perception. Psychopharmacology 152: 249-255. CrossRef Medline

Boucart M, Waucquier N, Michael GA, Libersa C (2007) Diazepam impairs temporal dynamics of visual attention. Exp Clin Psychopharmacol 15: 115-122. CrossRef Medline
Brainard DH (1997) The Psychophysics Toolbox. Spat Vis 10:433-436. CrossRef Medline

Choi H, Chang LH, Shibata K, Sasaki Y, Watanabe T (2012) Resetting capacity limitations revealed by long-lasting elimination of attentional blink through training. Proc Natl Acad Sci U S A 109:12242-122427. CrossRef Medline

Corbetta M, Patel G, Shulman GL (2008) The reorienting system of the human brain: from environment to theory of mind. Neuron 58:306 -324. CrossRef Medline

Di Lollo V, Kawahara J, Shabab Ghorashi SM, Enns JT (2005) The attentional blink: resource depletion or temporary loss of control? Psychol Res 69:191-200. CrossRef Medline

Dosenbach NU, Visscher KM, Palmer ED, Miezin FM, Wenger KK, Kang HC, Burgund ED, Grimes AL, Schlaggar BL, Petersen SE (2006) A core system for the implementation of task sets. Neuron 50:799-812. CrossRef Medline

Du F, Abrams RA, Zhang K (2011) Spatial distribution of the attentional blink. Front Psychol 2:360. CrossRef Medline

Edden RA, Puts NA, Harris AD, Barker PB, Evans CJ (2014) Gannet: A batch-processing tool for the quantitative analysis of gamma-aminobutyric acid-edited MR spectroscopy spectra. J Magn Reson Imaging 40:1445-1452. CrossRef Medline

Feinstein JS, Stein MB, Castillo GN, Paulus MP (2004) From sensory processes to conscious perception. Conscious Cogn 13:323-335. CrossRef Medline

Fragopanagos N, Kockelkoren S, Taylor JG (2005) A neurodynamic model of the attentional blink. Brain Res Cogn Brain Res 24:568-586. CrossRef Medline

Glennon M, Keane MA, Elliott MA, Sauseng P (2016) Distributed cortical phase synchronization in the EEG reveals parallel attention and working memory processes involved in the attentional blink. Cereb Cortex 26: 2035-2045. CrossRef Medline

Hommel B, Kessler K, Schmitz F, Gross J, Akyürek E, Shapiro K, Schnitzler A (2006) How the brain blinks: Towards a neurocognitive model of the attentional blink. Psychol Res 70:425-435. CrossRef Medline

Husain M, Nachev P (2007) Space and the parietal cortex. Trends Cogn Sci 11:30-36. CrossRef Medline

Kawahara JI, Kihara K (2011) No commonality between attentional capture and attentional blink. Q J Exp Psychol (Hove) 64:991-1008. CrossRef Medline

Kawahara J, Enns JT, Di Lollo V (2006) The attentional blink is not a unitary phenomenon. Psychol Res 70:405-413. CrossRef Medline

Kihara K, Takeda Y (2012) The relationship between phase synchronization frequency and temporal attention in the attentional blink. Jpn J Physiol Psychol Psychophysiol 30:243-254. CrossRef

Kihara K, Hirose N, Mima T, Abe M, Fukuyama H, Osaka N (2007) The role of left and right intraparietal sulcus in the attentional blink: A transcranial magnetic stimulation study. Exp Brain Res 178:135-140. CrossRef Medline

Kihara K, Yagi Y, Takeda Y, Kawahara JI (2011) Distractor devaluation effect in the attentional blink: Direct evidence for distractor inhibition. J Exp Psychol Hum Percept Perform 37:168-179. CrossRef Medline

Kristjánsson A, Nakayama K (2002) The attentional blink in space and time. Vision Res 42:2039-2050. CrossRef Medline

Lavie N (1995) Perceptual load as a necessary condition for selective attention. J Exp Psychol Hum Percept Perform 21:451-468. CrossRef Medline

MacLean MH, Arnell KM (2012) A conceptual and methodological framework for measuring and modulating the attentional blink. Atten Percept Psychophys 74:1080-1097. CrossRef Medline

MacLean MH, Arnell KM, Cote KA (2012) Resting EEG in alpha and beta bands predicts individual differences in attentional blink magnitude. Brain Cogn 78:218-229. CrossRef Medline

Marois R, Yi DJ, Chun MM (2004) The neural fate of consciously perceived and missed events in the attentional blink. Neuron 41:465-472. CrossRef Medline

Martens S, Wyble B (2010) The attentional blink: Past, present, and future of a blind spot in perceptual awareness. Neurosci Biobehav Rev 34: 947-957. CrossRef Medline

Martens S, Munneke J, Smid H, Johnson A (2006) Quick minds don't blink: Electrophysiological correlates of individual differences in attentional selection. J Cogn Neurosci 18:1423-1438. CrossRef Medline

Mayr U, Diedrichsen J, Ivry R, Keele SW (2006) Dissociating task-set selec- 
tion from task-set inhibition in the prefrontal cortex. J Cogn Neurosci 18:14-21. CrossRef Medline

Mullins PG, McGonigle DJ, O'Gorman RL, Puts NA, Vidyasagar R, Evans CJ, Edden RA (2014) Current practice in the use of MEGA-PRESS spectroscopy for the detection of GABA. Neuroimage 86:43-52. CrossRef Medline

Olivers CN, Meeter M (2008) A boost and bounce theory of temporal attention. Psychol Rev 115:836-863. CrossRef Medline

Olivers CN, Nieuwenhuis S (2005) The beneficial effect of concurrent taskirrelevant mental activity on temporal attention. Psychol Sci 16:265-269. CrossRef Medline

Olivers CN, Nieuwenhuis S (2006) The beneficial effects of additional task load, positive affect, and instruction on the attentional blink. J Exp Psychol Hum Percept Perform 32:364-379. CrossRef Medline

PelliDG (1997) TheVideoToolbox software for visual psychophysics: transforming numbers into movies. Spat Vis 10:437-442. CrossRef Medline

Potter MC, Staub A, O'Connor DH, Potter MC (2004) Pictorial and conceptual representation of glimpsed pictures. J Exp Psychol Hum Percept Perform 30:478-489. CrossRef Medline

Raffone A, Srinivasan N, van Leeuwen C (2014) The interplay of attention and consciousness in visual search, attentional blink and working memory consolidation. Philos Trans R Soc Lond B Biol Sci 369:20130215. CrossRef Medline

Raymond JE, Shapiro KL, Arnell KM (1992) Temporary suppression of visual processing in an RSVP task: an attentional blink? J Exp Psychol Hum Percept Perform 18:849-860. CrossRef Medline

Seiffert AE, Di Lollo V (1997) Low-level masking in the attentional blink. J Exp Psychol Hum Percept Perform 23:1061-1073. CrossRef

Simione L, Raffone A, Wolters G, Salmas P, Nakatani C, Belardinelli MO, van Leeuwen C (2012) ViSA: a neurodynamic model for visuo-spatial working memory, attentional blink, and conscious access. Psychol Rev 119: 745-769. CrossRef Medline

Taatgen NA, Juvina I, Schipper M, Borst JP, Martens S (2009) Too much control can hurt: A threaded cognition model of the attentional blink. Cogn Psychol 59:1-29. CrossRef Medline

Wyble B, Bowman H, Nieuwenstein M (2009) The attentional blink provides episodic distinctiveness: sparing at a cost. J Exp Psychol Hum Percept Perform 35:787-807. CrossRef Medline 